\title{
Development Methodology Contemporary Islamic Economics
}

\author{
Muhamad Wahyudi ${ }^{1}$, Izzani Ulfi ${ }^{2}$, Ujang $\mathrm{SM}^{3}$, Menur Kusumaningtiyas ${ }^{4}$ \\ wahyudi_arridho@untidar.ac.id ${ }^{1}$, ujang@uniska-kediri.ac.id,izzani.ulfi-2019@feb.unair.ac.id \\ Universitas Tidar ${ }^{1}$, Universitas Islam Kadiri ${ }^{2}$, Universitas Airlangga ${ }^{3}$
}

\begin{abstract}
As a new branch of Islamic economics, it still needs further discussion and studies to get a solid scientific building as a science. There are various methods and approaches used in developing Islamic economics. This difference is certainly caused by the diversity of viewpoints and scientific backgrounds used in developing Islamic economics. The development of Islamic economic practices today has so far entered into various fields in human economic life. The development of Islamic economics in terms of this practice must certainly be supported by the availability of a complete and well-established economic theory. This paper will review how the methodology is suitable and relevant in order to develop the theory of Islamic economics today.
\end{abstract}

Keywords: Methodology, Islamic Economics, Counterparts

\section{Pendahuluan}

Ada ima alasan pentingnya merumuskan metodologi ekonomi Islam [1]. Pertama metodologi merupakan pintu lahirnya teori-teori baru. Kedua, kajian metodologi dibutuhkan dalam rangka menetapkan prosedur, standar, dan kriteria ilmiah dalam menilai sebuah teori. Ketiga, metodologi dipakai untuk menguji teori dengan fakta empiris. Keempat, metodologi menjadi penghubung aspek ontologis dan aksiologis sebuah bangunan teori. Kelima, keberadaan metodologi menjadi solusi atas kesenjangan dalam mempelajari ekonomi Islam. Ekonom muslim telah menawarkan berbagai pendekatan yang dapat ditempuh dalam membangun ekonomi Islam seperti Monzer Khan, Fahim Khan, Masudul Alam Chudhury, M Aslam Haneef dan Hafas Furqani [2].

Keberagaman pikiran itu bisa kita temukan dari pemikir-pemikir Islam kotemporer seperti pemikiran Monzer Kahf [3], Abdel-Rahman Yousri Ahmed [4], M Akram Khan [5], M Abdul Mannan [6]. Termasuk juga penelitian yang membahas pemikiran beberapa ekonom muslim yang berkaitan dengan metodologi ekonomi Islam dalam satu penelitian, diantaranya adalah berkaitan dengan konstruksi keilmuan [7], [8] dan perlunya metodologi yang berbeda dengan yang lain [9]. Furqoni, (2016) mengklasifikasikannya kedalam tiga klaisifikasi pendekatan (1) metodologi usul al fiqh, (2) metodologi pluralisme, dan (3) metodologi Islamisasi.

Melalui paper ini akan dikaji metodologi pengembangan ilmu ekonomi Islam kontemporer saat ini?. Pendekatan yang digunakan adalah kepustakaan (library reesarch). Data berupa pemikiran metodologi ekonomi Islam dari pemikir islam kontemporer. diperoleh dari portal online dan sumber offline. Data kemudian dianalisis menggunakan teknik analisis data kualitatif, dideskripsikan secara analitis untuk menjabarkan jawaban masalah penelitian. 


\section{Tinjauan Pustaka}

\section{Metodologi, Epistemologi dan Lahirnya Ilmu Baru}

Metodologi bisa pahami sebagai bagian khusus dari cabang filsafat yang disebut dengan epistemologi. Dalam epistemologi, kita mempelajai teori pengetahuan, sumber-sumber pengetahuan, penerapan ilmu pengetahuan, dan batasan-batasan ilmu pengetahuan. Sementara metodologi, objek kajiannnya lebih spesifik, yaitu bagaimana kita mengembangkan ilmu pengetahuan (teori) dan bagaimana mengevaluasi pengetahuan (teori) yang dihasilkan [1] Metodologi, sebagaimana didefinisikan oleh Louay Safy dalam [11] adalah bidang penelitian ilmiah untuk mencapai dasar kebenaran, deskripsi, penjelasan tentang aturan-aturan dan prosedur dengan metode ilmiah. Glen Fox melihat metodologi terkait dengan penilaian teori. Sementara Mohammed Aslam Haneef melihat metodologi ekonomi sebagai pembahasan dan analisis mengenai proses pembentukan model, pengembangan teori, pengujian hipotesis, serta penetapan dan penggunaan standar untuk mengevalusi proses tersebut.

Muhammad Akram Khan memandang metodologi menyelidiki konsep, teori, dan prinsip-prinsip dasar penalaran terkait dengan subjek. Para ekonom seringkali sangat memperhatikan persoalan ini dan kerapkali mencuatkan perdebatan hangat [12]. Metodologi memberikan argumen, mungkin juga rasionalisasi, yang mendukung berbagai pilihan yang dimiliki oleh komunitas ilmiah untuk aturan dan prosedur ilmiah tertentu, termasuk menciptakan konsep, membangun teori, merumuskan hipotesis, dan menguji teori [13].

Ilmu lahir dari interaksi antara worldview dan realitas sosial masyarakat yang menghasilkan tradisi ilmiah dan berakhir dengan lahirnya sebuah teori baru [14]. Metodologi bagi Safi (1996) bukanlah tentang metode, teknik, proses atau prosedur, tetapi metodologi mengkaji bagaimana bisa menjustifikasi dan menjelaskan hukum dan prosedur ilmiah dalam mengkaji alam dan manusia Beberapa penelitian tentang metodologi ekonomi Islam, diantarannya Monzer Kahf [3], Abdel-Rahman Yousri Ahmed [4], M Akram Khan [5], M Abdul Mannan [6]. Yang berkaitan dengan konstruksi keilmuan [7], [8], perlunya metodologi yang berbeda dengan yang lain [9]. M. Abdul Mannan, Monzer Kahf, M Akram Khan, M Aslam Haneef dan Abdel Rahman Yousri Ahmed dan sebagainya

\section{Pembahasan}

Terdapat tiga tantangan yang dihadapi para ekonom dan akademisi muslim yang akan mengembangkan ekonomi Islam yaitu fondasi displin (the founations of discipline), fondasi epistemologi (the epistemological foundations) dan fondasi etik (the ethical foundations) [5]. Fondasi displin (the founations of discipline), merupakan tantangan dalam menetapkan fondasi disiplin ilmu yang bersumber dari pandangan dunia Islam (Islamic worldview) yang merupakan satu kesatuan yang komprehensif antara piritual dan fisik, fenomena tak terlihat dan terlihat, jiwa dan badan, kehidupan dunia dan ahkirat dalam ruang lingkup individu masyarakat dan negara. Tantangan fondasi epistemologi (the epistemological foundations) merupakan tantangan dalam merumuskan epistemologis ilmu ekonomi Islam yang bersumber dari wahyu, akal, dan fakta/pengalaman, dalam kerangka Islamic worldview. Tantanga fondasi etik (the ethical foundations). Merupakan tantangan dalam membangun fondasi fondasi etik yang digali dari nilai-nilai etika dalam Al-Quran.

Ekonomi Islam kini telah menjadi trend aktivitas ekonomi dibanyak negara. Ekonomi Islam telah merambah hingga ke sektor terkecil yaitu rumah tangga. Kecendrungan seorang muslim berkaktivitas ekonomi dengan konsep Islam begitu tinggi [20]. Kini sangat mudah menemukan fakta-fakta empiris, realitas-realitas sosial praktik ekonomi Islam di sekitar kita. Hal ini menjadi suatu fenomena baru sangat penting peranannya dalam mengembangkan teoriteori baru tentang ekonomi Islam. Dalam konteks saat ini dua pendekatan yang relevan dengan 
perkembangan ekonomi Islam yang begitu masif. Pendekatan bahwa Islamisasi dan telaah kiritis tradisi intelektual Islam (turats) merupakan pilihan yang tepat. Pendekatan Islamisasi merupakan telaah kritis atas disiplin ilmu-ilmu modern dengan mengeliminasi nilai-nilai yang tidak sejalan dengan norma-norma Islam menjadi suatu teori ekonomi yang Islami. Metode telaah kiritis adalah evaluasi kritis tradisi intelektual Islam (turats) dengan merelevansikannya sesuai dengan kebutuhan kontemporer. Metodologi Islamisasi dikombinasikan dengan model pengembangan ilmu ekonomi Islam, yang memberikan tambahan empat kriteria bagi sebuah teori baru yakni A clear subject-matter, methodology to appraise theories (metode untuk menilai teori), systematic accumulation of knowledge, dan a well-organised body of knowledge.

A clear subject-mattern (objek kajian). Sebuah ilmu harus mempunyai obyek kajian yang jelas (materi (pelajaran) yang jelas. Pengembangan ilmu ekonomi Islam harus mampu menjawab pertanyaan apa subject-matter dari teori yang akan dihasilkan. Apa subject-matter dalam ekonomi Islam? ada empat macam yaitu pertama studi tentang tentang prinsip dan aturan syariah, Kedua, studi tentang cara untuk mewujudkan tujuan Islam dalam ekonomi. Ketiga, studi tentang cara untuk memecahkan masalah ekonomi dalam kerangka Islam. Keempat, Ekonomi Islam sebagai studi perilaku manusia (manusia Islam) dalam membuat pilihan dan keputusan. M Abdul Mannan, Zaim, M Aslam Haneef, M Nejatullah Siddiqi dan Yousri. Haneef mendefiniskan subject-matter ekonomi Islam adalah usaha untuk menafsirkan dan memecahkan masalah ekonomi manusia berdasarkan nilai-nilai, norma, hukum dan institusi yang ditemukan di, dan berasal dari, sumber pengetahuan dalam Islam [24].

Methodology to appraise theories adalah metodologi yang dipakai dalam menilai kebasahan dari suatu rumusan teori, formula, kriteria penerimaan dan penolakan atas temuan teori baru. Methodology to appraise theories dibutuhkan dalam rangka (1) untuk menghasilkan teori ekonomi yang dapat menghubungkan antara doktrin dan kenyataan praktis. (2) untuk menghasilkan teori ekonomi yang dapat menjelaskan realitas dan hubungannya secara totalitas. (3) untuk menghasilkan teori ekonomi yang dapat membantu dalam merealisasikan tujuan [25]. Tahapan dalam menilai teori dimulai identifikasi ide atau masalah yang kemudian dikombinasikan dengan sumber pengetahuan dari wahyu, akal dan fakta untuk membangun hipotesis. Hiptesis yang terbentuk kemudian di uji secara internal integrity dan relational unity. Selanjutnya di evaluasi agar layak menjadi teori baru yang baik. Teori yang baik harus didasarkan pada prinsip ajaran Islam, harus mampu melakuka analisis ekonomi rasional yang konsisten dengan asumsi dan perilaku ekonomi, dan harus mampu menerjemhankan ke dalam aplikasi praktis [15]. Subuah teori atau ilmu dikatakan akan mendapatkan legitimasinya, manakala teoriatau ilmu itu secara kontinyu mengalami perkembangan. Lairnya suatu teori baru harus diikuti dengan lahirnya teori-teori lainnya secara sistematis dan berkesinambungan. Inilah yang disebut dengan Systematic Accumulation of Knowledge. Keberlangsungan eksistensi sebuah ilmu akan terlihat dari panjangnya durasi ilmu tersebut mengalami proses perkembangan dari waktu ke waktu. Menilik pada durasi perkembangan ilmu ekonomi Islam sendiri membagi ke dalam tiga periode yaitu periode klasik, periode transisi dan periode kontemporer.

Syarat lain yang harus dipenuhi agar ekonomi Islam dapan disebut sebagai disiplin ilmu baru adalah memiliki tubuh pengetahuan yang lengkap. Membandingkan dengan ekonomi konvensional yang sudah mengalami masa pengembangan selama 250 tahun, ekonomi Islam baru mengalami 30-50 tahun yang lalu. Ekonomi Islam 'kontemporer' sebagai sebuah sistem yang memiliki body of knowledge ketika di masa abad ke-20 ini. Ekonomi Islam msih dalam proses melengkapi diri untuk menjadi disiplin ilmu baru dan masih dalam pencarian identitas [27]. Pertanda formal kelahiran ekonomi Islam adalah penyelenggaraan konferensi pada tahun 
1976 sebagai penegasan kelahiran ekonomi Islam sebagai cabang ilmu baru [28]. Lambat laun kemunculan teori dalam ilmu ekonomi Islam semakin banyak.

Salah satu pemikiran dalam rangka membangun body of knowledge ekonomi Islam adalah buku Islamic Economic yang diterbitkan oleh ISRA Malaysia [29]. Buku tersebut secara garis besar membahas masalah fondasi ilmu ekonomi Islam (metodologi ekonomi Islam), mikro ekonomi Islam (produksi, distribusi dan konsumsi), makro ekonomi Islam kebijakan fiskal dan moneter, sistem keuangan Islam (pasar modal dan perbankan) dan pembangunan Islam (kemiskinan dan pertumbuhan) dan isu penting lainnya.

\section{Kesimpulan}

Metode Islamisasi ilmu pengetahuan merupakan salah satu metode dari sekian metode yang di hasilkan oleh para pemikir ekonomi Islam saat ini. lslamisasi ilmu pengetahuan di Indonesia dilakukan dengan cara merekonstruksi struktur paradigmatik ilmu-ilmu keIslaman zaman modern bercorak integralistik dalam tiga variasi, yaitu: integratif-revitalistik, integratifinterkonektif, dan integnatif-transformatif terapan (amali). Rekonstruksi ilmu pengetahuan keIslaman zaman kekinian dalam konteks keindonesiaan dilakukan dengan cara dekonstruksi atau membongkar adagium-adagium keilmuan modern dan ilmu keIslaman klasik untuk kemudian dicari dan disusun kembali dengan menekankan aspek relevansinya dan manfaatnya. Berkaitan dengan upaya itu, ada empat pola dasar yang digunakan oleh kalangan intelektual Muslim Indonesia dalam upaya melakukan rekonstruksi ilmu pengetahuan zaman modern. Pertama, mengubah tata pikir normatif menjadi teoritis. Kedua, mengubah tradisi ideologis menjadi rasional-empirik. Ketiga, mengubah tradisi penyakralan pemikiran menjadi kritik terhadapnya. Keempat, mengubah cara berpikir yang menekankan penguasaan materi menjadi penekanan epistemologi.

\section{References}

[1] A. Ubaidilah, "Membangun Fondasi Keilmuan Ekonomi Islam: Telaah Metodologi Muhammad Akram Khan," JES, vol. 1, no. 2, pp. 152-170, 2017.

[2] H. Furqani, "Signifikansi kajian metodologi dalam pengembangan body of knowledge ekonomi Islam," Equilib. J. Ekon. Syariah, vol. 4, no. 1, pp. 179-194, 2016.

[3] A. Ubaidillah, "Metodologi Ilmu Ekonomi Islam Monzer Kahf," JES, vol. 2, no. 2, 2018.

[4] A. Ubaidillah, "Menelusuri Metodologi Ekonomi Islam Abdel-Rahmab Yousri Ahmed," JES, vol. 2, no. September, pp. 1-22, 2017.

[5] A. Ubaidillah, "Meembangun Fondasi Keilmuan Ekonomi Islam: Telaah Metodologi Muhammad Akram Khan," JES, vol. 1, no. 2, 2017.

[6] A. Mughits, "Epistemologi Ilmu Ekonomi Islam (Kajian atas Pemikiran M . Abdul Mannan dalam Teori dan Praktek Ekonomi Islam )," Hermeneia, J. Kaji. Islam Interdisip., vol. 2, no. 2, pp. 173 195, 2003.

[7] Y. D. Sanrego Nz, "Membangun Konstruksi Keilmuan Ekonomi Islam," Islamica, vol. 5, no. 1, 2010.

[8] D. Nurohman, "Hakikat dan Konstruksi Keilmuwan Ekonomi Islam," Episteme, vol. 7, no. 2, 2012.

[9] M. H. Sawit, "Metodologi penelitian ekonomi islam: perlukah berbeda?," JEP, vol. 3, no. 1, pp. 19-28, 1998.

[10] H. Furqoni, "Pembangunan Ekonomi Islam Dengan Tipologi Ilmiah,” Maqdis J. Kaji. Ekon. Islam, vol. 1, no. 1, pp. 83-96, 2016.

[11] M. A. Haneef and H. Furqani, "Methodology of Islamic Economics: Overview of present state and future direction," Int. J. Econ. Manag. Account., vol. 1, no. 1, pp. 1-26, 2011.

[12] T. Khan, "Islamic economics: Where From, where To? Muhammad Nejatullah Siddiqi," J. King Abdulaziz Univ. Islam. Econ., vol. 27, no. 2, pp. 95-103, 2014, doi: 10.4197/Islec.27-2.7. 
[13] Z. Hasan, "Islamization of knowledge in economics Issues and agenda," IIUM J. Econ. Manag., vol. 6, no. 2, pp. 1-40, 1998.

[14] N. Irkhami, "Worldview dan Epistemologi dalam Ilmu Ekonomi Islam," J. Ijtihad, vol. 10, no. 2, pp. 1-21, 2010.

[15] H. Furqani and Hanee, "Theory appraisal in Islamic economic methodology: purposes and criteria," Humanomics, vol. 28, no. 4, pp. 270-284, 2012, doi: 10.1108/08288661211277335.

[16] M. Kahf, "Islamic Economic: Notes on Definition and Methodology," Rev. Islam. Econ., vol. 13, pp. 23-47, 2003.

[17] M. A. Mannan, "Islamic Economics as a Social Science: Some Methodological Issues," J. Res. Islam. Econ., vol. 1, no. 1, pp. 41-50, 1983.

[18] M. A. Khan, "Methodology for Theory Building in Islamic Economic," J. Islam. Econ. Bank. Financ., vol. 10, no. 2, 2014.

[19] H. Furqani, "Foundational challenges in the construction of an Islamic economics discipline," Int. J. Plur. Econ. Educ., vol. 6, no. 4, p. 324, 2015, doi: 10.1504/ijpee.2015.075856.

[20] T. N. Fitria, "Kontribusi Ekonomi Islam Dalam Pembangunan Ekonomi Nasional," J. Ilm. Ekon. Islam, vol. 2, no. 03, pp. 29-40, 2016.

[21] M. A. Haneef and H. Furqani, "Developing the Ethical Foundations of Islamic Economics: Benefitting from Toshihiko Izutsu,” pp. 173-199, 2009.

[22] H. Furqani, "Definition of Islamic economics as a discipline: Challenges in the clarification and classification," 10th Int. Conf. Islam. Econ. Financ., 2015.

[23] H. Furqani, "Defining Islamic Economics : Scholars' Approach, Clarifying The Nature, Scope and Subject-Matter of The Discipline," Tujise Turkish J. Islam. Econ., vol. 5, no. 2, pp. 69-94, 2018, doi: $10.26414 / \mathrm{m} 025$.

[24] M. Aslam and M. Haneef, "Islam, The Islamic Worldview, and Islamic Economics," IIUM J. Econ. Manag., vol. 5, no. 1, pp. 39-65, 1997.

[25] H. Furqani, "Pembangunan ekonomi Islam dengan tipologi ilmiah," Maqdis (Jurnal Kaji. Ekon. Islam., vol. 1, no. 1, 2016.

[26] H. Furqani, "The Disciplines in the making: Appraising the progress of Islamic Economics," $J$. Islam. Monet. Econ. Financ., 2015.

[27] A. C. Mahomedy, "Islamic economics: Still in search of an identity," Int. J. Soc. Econ., vol. 40, no. 6, pp. 556-578, 2013, doi: 10.1108/03068291311321857.

[28] M. A. Haneef and H. Furqani, "Usul al-Iqtisad: The Missing Dimension in Contemporary Islamic Economic and Finance," in Reading in Islamic Economic and Finance, 2007.

[29] A. Abdullah and Et.all, Islamic Economics: Principles \& Analysis. Kuala Lumpur: International Shari'ah Research Academy for Islamic Finance, 2018. 